\title{
Preoperative echocardiographic diagnosis of anterior mitral valve leaflet fenestration associated with infective endocarditis
}

\author{
MASAYUKI MATSUMOTO, JOEL STROM, “ HAJIME HIROSE, HIROSHI ABE \\ From the Division of Cardiology, The First Department of Medicine and the First Department of Surgery, \\ Osaka University Medical School, Osaka, Fapan
}

SUMMARY Previously unreported echocardiographic findings are described of two cases with anterior mitral valve leaflet fenestration associated with infective endocarditis. M-mode echocardiograms demonstrated a periodic interruption in the echo tracing of the mitral valve ring area. Long axis real time two dimensional echocardiograms showed an echo defect in the body portion of the anterior mitral valve leaflet. Preoperative echocardiographic diagnosis was confirmed at surgery and echocardiographic findings correlated well with surgical findings.

The usefulness of echocardiography in detecting vegetations and torn chordae of mitral valve leaflets is well known. ${ }^{1-4}$ We do not see, however, reports on the echocardiographic diagnosis of perforated mitral valve leaflets, which is also an important complication of infective endocarditis. 5 In this communication we describe our recent experience of two cases with perforated anterior mitral valve leaflet complicated by infective endocarditis.

\section{Case 1}

A 31 year old woman was referred for assessment of valvular disease. This patient had suffered from infective endocarditis at the age of 17 and was diagnosed as having mitral valve regurgitation three years later. Elective surgery was planned and echocardiography and angiography were performed before that.

$M$-mode echocardiograms showed a very dilated left atrium with an anteroposterior diameter of $64 \mathrm{~mm}$ and left ventricular end-systolic and end-diastolic diameters of $50 \mathrm{~mm}$ and $73 \mathrm{~mm}$, respectively. Movements of both the ventricular septum and posterior left ventricular wall were increased. The echo from the body of the anterior mitral valve leaflet was interrupted in early diastole by a disappearance of the D-E slope of the echo tracing.

A long axis real time two dimensional echocardiogram showed an echo defect on the body portion of the

*Present address: Division of Cardiology, Department of Medicine, Albert Einstein College of Medicine, Bronx, New York, USA.

Accepted for publication 2 September 1982 anterior mitral valve leaflet, indicated by an arrow on Fig. 1A. With a slight lateral rotation of the transducer the echo defect increased its size to $10 \mathrm{~mm}$. A small flap-like echo was observed near this defect and it moved into the left atrium in systole and into the left ventricular outflow tract in diastole.

A short axis real time two dimensional echocardiogram at the level of the left ventricular outflow tract visualised an echo defect of $8 \mathrm{~mm}$ at the lateral portion of the body of the anterior mitral valve leaflet (arrow in Fig. 1B). At operation a round fenestration of $16 \times 12$ $\mathrm{mm}$ in size was confirmed (Fig. 2). A pericardial patch was sutured and annuloplasty was performed. Postoperative long axis real time two dimensional echocardiograms no longer showed the echo defect, multiple layered echoes being recorded at the sutured portion of the defect instead.

\section{Case 2}

A 33 year old woman was known to have been a drug addict for years. After physical examination, combined aortic and mitral valve disease was suspected and the patient was referred for echocardiographic examination. M-mode echocardiogram showed a wide bandlike echo at the aortic valve recording position. A periodic interruption was observed in the echo tracing of the mitral valve ring area. Long axis real time two dimensional echocardiograms showed a huge mass echo which ejected into the aorta in systole and receded into the left ventricular outflow tract in diastole (Fig. $3 \mathrm{~A}$ and $\mathrm{B}$ ). In systole a defect was observed in the echo from the body portion of the anterior mitral valve 

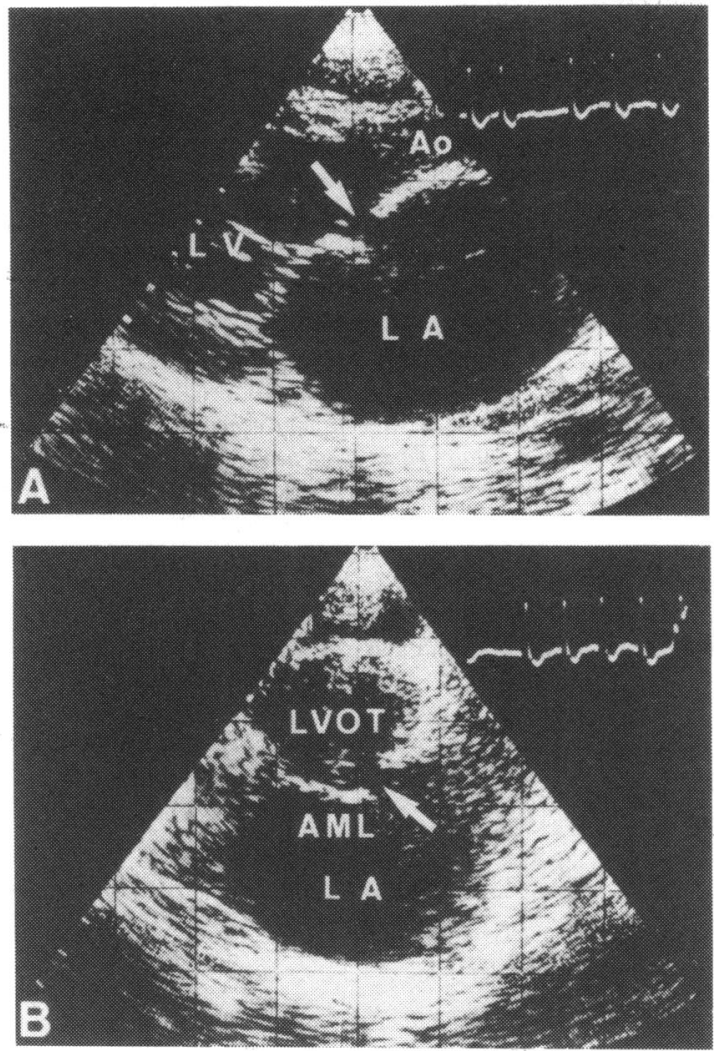

Fig. 1 (A) A long axis real time two dimensional echocardiogram in systole showing a fenestration in the anterior mitral valve leaflet (arrow). Ao, aorta; $L V$, left ventricle; $L A$, left atrium. (B) $A$ short axis real time two dimensional echocardiogram in systole showing a fenestration in the anterior mitral valve leaflet (arrow). LVOT, left ventricular outflow tract; $A M L$, anterior mitral leaflet.

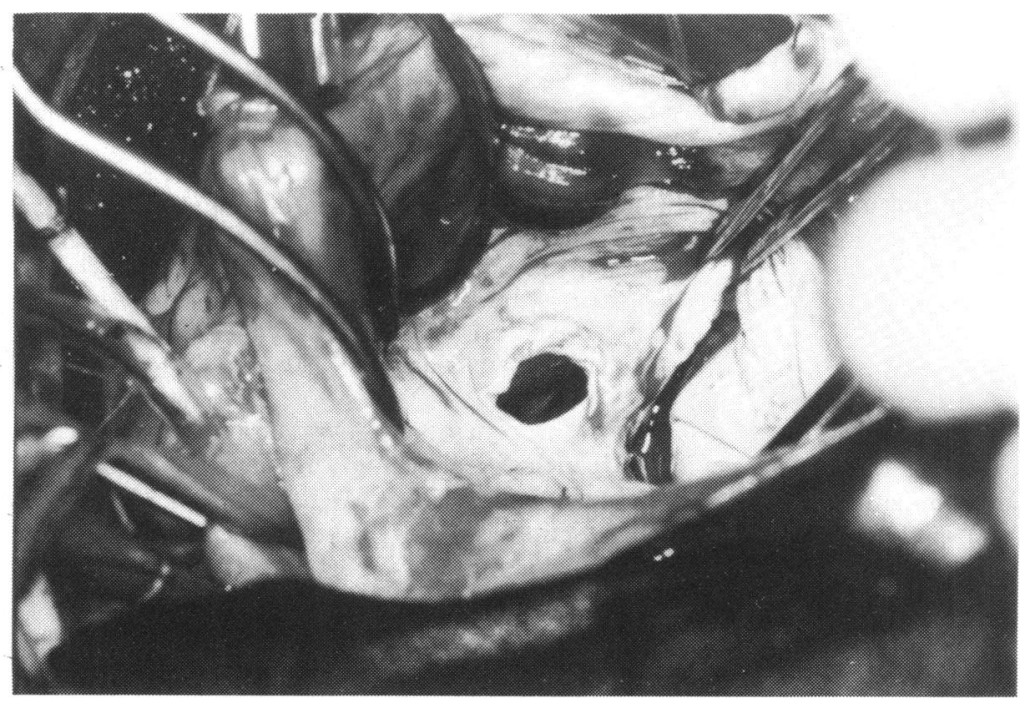

Fig. 2 The operative finding of a fenestration in the anterior mitral valve leaflet viewed from the left atrium. 


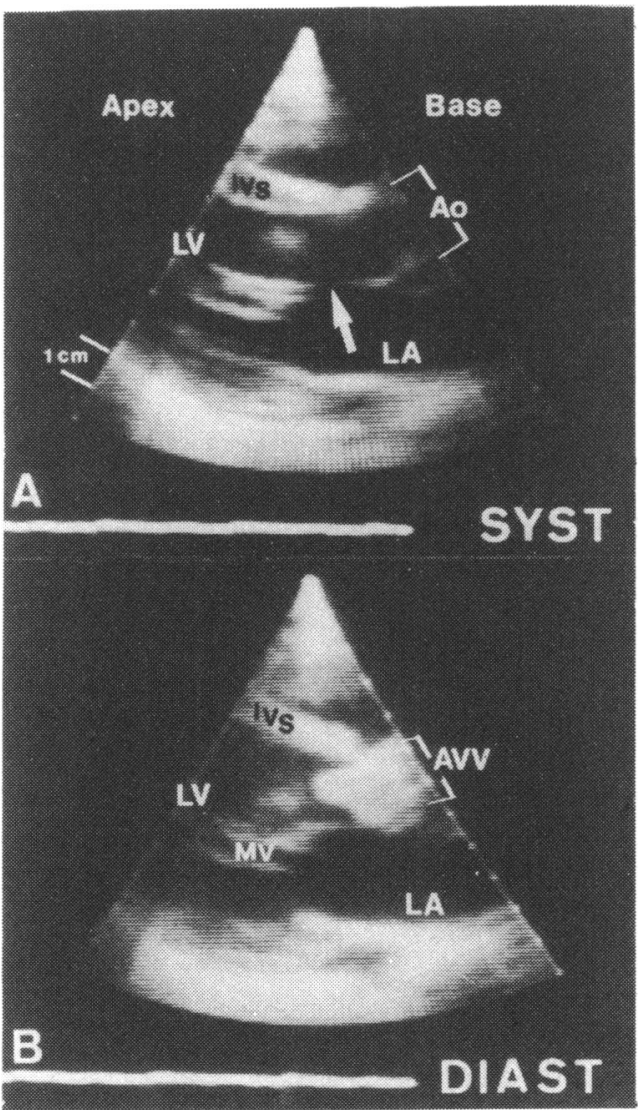

leaflet, but in diastole this defect was not recognisable because of the huge mass echo receding into the outflow tract. At operation a tear in the body of the anterior mitral valve leaflet resembling a fissure and a huge aortic valve vegetation were confirmed.

\section{Comment}

To our knowledge no reports have been published on echocardiographic features of mitral valve perforation resulting from infective endocarditis. Our two recent cases indicate that echocardiography can make this diagnosis.

\section{References}

1 Andy JJ, Sheikh MU, Ali N, et al. Echocardiographic observations in opiate addicts with active infective endocarditis. Frequency of involvement of the various valves
Fig. 3 (A) Long axis real time two dimensional echocardiograms in systole (panel $A$ ) and diastole (panel $B$ ). The arrow in panel $A$ indicates a tear in the body portion of the anterior mitral valve leaflet. In diastole the tear in the mitral valve leaflet is not recognisable because of the huge mass echo receding into the left ventricular outflow tract which is in contact with the tear. $A V V$, aortic valve vegetation; IVS, interventricular septum; $M V$, mitral valve. Other abbreviations as in Fig. $l$. and comparison of echocardiographic features of right- and left-sided cardiac valve endocarditis. Am $\mathcal{F}$ Cardiol 1977; 40: 17-23.

2 Miller $\mathrm{MH}$, Casey JI. Infective endocarditis: new diagnostic techniques. Am Heart $\mathcal{F}$ 1978; 96: 123-8.

3 Strom J, Becker R, Davis R, et al. Echocardiographic and surgical correlations in bacterial endocarditis. Circulation $1980 ; 62$, suppl I: I-164-7.

4 Sheikh MU, Covarrubias EA, Ali N, Lee WR, Sheikh NM, Roberts WC. M-mode echocardiographic observations during and after healing of active bacterial endocarditis limited to the mitral valve. Am Heart F 1981; 101: 37-45.

5 Weinstein L. Infective endocarditis. In: Braunwald E, ed. Heart disease. A textbook of cardiovascular medicine. Philadelphia: W B Saunders, 1980: 1188.

Requests for reprints to Dr Masayuki Matsumoto, Central Cardiac Laboratory, Division of Cardiology, The First Department of Medicine, Osaka University Medical School, 1-1-50 Fukushima, Fukushima-ku, Osaka 553, Japan. 